\title{
MOISTURE EXPANSION OF GLAZES AND OTHER CERAMIC FINISHES
}

\author{
By H. G. Schurecht and G. R. Pole ${ }^{1}$
}

ABSTRACT

Research for ascertaining why some glazes are more resistant to "moisture crazing" than others revealed the fact that certain glazes expand, because of the action of water, similarly to some of the ceramic bodies to which they are applied. Although a control of this type of expansion is very important in fitting glazes to bodies, it has not been previously considered. Its importance should be evident at once when it is considered that a large "moisture expansion" in a glaze, or other finish, is in many cases an indication that the glaze will not be so liable to craze when the ceramic ware of material on which it is used is exposed to moisture. This follows since the glaze and the body on which it goes and which is ordinarily very susceptible to this kind of expansion will then increase in size simultaneously and more nearly at the same rate. Such conditions lessen the tendency of the body expansion to cause tensile stresses in the glaze.

In this investigation specimens of various finishes were subjected to steam at 150 lbs./in. ${ }^{2}$ for an hour because it was known that this treatment of such peaterials produces similar effects to those caused by long exposure to weather. This artificial weathering treatment caused in lustrous glazes an average expansion of 0.004 per cent, in mat glazes 0.011 per cent, in vitreous slip finishes 0.005 per cent, and in porous slip finishes 0.033 per cent. The moisture expansion of one of the mat glaqes was 30 per cent of the average obtained for a ceramic body having an absorption of approximately 12 per cent. This proclivity of ceramic finishes to expand by the absorption of moisture can be controlled in their manufacture.

CONTENTS

I. Introduction

II. Experimental methods

III. Results on bars of ceramic finishes............

IV. Results with ceramic finishes on rings .

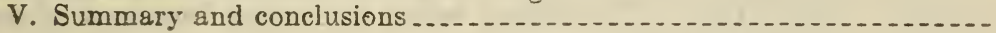

\section{INTRODUCTION}

It has been shown ${ }^{2}$ that a type of delayed crazing found on glazed ceramic ware may, in certain cases, be caused by a gradual exp\&nsion produced by the action of moisture on the body during storage or use. It has also been demonstrated that by subjecting glazed bodies to steam at a pressure of $150 \mathrm{lbs} . / \mathrm{in} .^{2}$ some of the effects produced are very similar to those obtained by exposure to weather. Moreover it was found ${ }^{3}$ that this type of crazing may be prevented by adjusting the relative expansivity of the glaze with respect to the body so that the glaze is under a fairly high compression when the ware is removed from the kiln.

1 Research associates of the National Terra Cotta Society at the National Bureau of Standards.

' Methods for Testing Crazing of Glazes Caused by Increases in Size of Cersmic Bodies, J. Am. Cer. Soc., 11, pp. 271-277; 1928.

3 Effect of Water on Expansions of Ceramic Bodies of Different Compositions, B. S. Jour., Research, 3. pp. 331-341; 1929; J. Am. Ceram. Soc., 12, pp. 596-601; 1929. 
Preliminary studies indicated, however, that some of the porous slip finishes or engobes develop a "moisture expansion" similar in magnitude to that obtained in the body on which they go, and, hence, that it is unnecessary to have such finishes in high compression in order to prevent "moisture crazing:" It was also found that some glazes may be in less compression than others to prevent such crazing. This led to the belief that these glazes as well as the engobes develop a moisture expansion. The investigation was, therefore, continued to test this opinion, and the results to date evidently confirm it.

\section{EXPERIMENTAL ME'THODS}

Four different lustrous glazes, 5 mat glazes, 5 porous slip finishes, and 2 vitreous slip finishes were studied in this investigation. In one portion of the tests, bars of the glazes and other ceramic finishes, approximately 1 by 1 by 6 inches in size, were used as specimens. These bars were made by filling fire-clay troughs with the raw glazes, or engobes, and firing them to the regular maturing temperatures of the finishes. These temperatures ranged from cones 3 to 6 . After firing, the fire-clay troughs were ground from the fused bars of glazes and engobes. Pyrex glass capillary reference tubes were then cemented in grooves which had been cut about 5 inches apart in the bars. The distances between these tubes were measured by means of a microscope comparator ${ }^{4}$ and the bars were then subjected to steam at a pressure of $150 \mathrm{lbs}$./in. ${ }^{2}$ in an autoclave for one hour. After this treatment the specimens were cooled and the distances between the reference marks remeasured in order to determine the expansions produced. The specimens were then subjected to steam at a pressure of $300 \mathrm{lbs}$./in. ${ }^{2}$ for another hour to determine the additional expansion caused by this more severe treatment.

In another test, the same finishes were applied to the outside surfaces only of cylindrical rings having 2 -inch outside diameters as described in a previous article. ${ }^{5}$ Each finish was tested on rings of the same bodies for which it was developed by the manufacturer. Two reference marks consisting of thin capillary pyrex tubes cemented in holes approximately one-fourth inch apart were established on the upper edge of each ring. The rings were cut open between these reference marks whose distances apart were then measured with a micrometer microscope. After this, the rings were subjected to steam at a pressure of $75 \mathrm{lbs}$./in. ${ }^{2}$ for one hour in an autoclave and cooled for a remeasurement of the distances between the marks. The increases noted in these distances resulted because the effect of moisture, absorbed during the treatment, expanded the finishes less than it did the bodies of the rings. When different finishes are on rings having the same body these increases become larger, therefore, as the susceptibility of the finishes to moisture expansion decreases. The results obtained are given in Table 2, and represent in every case the average obtained on three duplicate specimens after corrections were made for any discrepancy occurring in the temperatures at which the measurements were made. The variations between the results obtained on duplicates were usually less than $\pm 0.001 \mathrm{~cm}$.

- The comparator used in this work was designed by C.S. Laubly, of the National Bureau of Standards, and is described in Shrinkage of Portland Cement, by J. C. Pearson, Am. ('oncrete Inst.; 1921.

- Methods of Moasuring Strains Between Glazes and Ceramic Bodies, B. S. Jour. Research, 5, pp. 97103; 1903; J. Am. Ceram. Soc., 13, pp. 369-375; 1930 . 
To determine the degree to which these finishes are subject to crazing as a result of this differential moisture expansion between them and the bodies, crazing tests were carried out on 4 by 4 by 1 inch tile made of the appropriate bodies as in the case of the rings. In these tests the treatment was the same as in the ring tests except that a second treatment at a steam pressure of $150 \mathrm{lbs}$./in. ${ }^{2}$ was also given. The results are incorporated in Table 2.

\section{RESULTS ON BARS OF CERAMIC FINISHES}

The results obtained on the bars made of the glazes and other ceramic finishes are given in Table 1.

The lustrous glazes developed moisture expansions ranging between 0.001 and 0.009 per cent with an average of 0.004 per cent when treated with steam at a pressure of $150 \mathrm{lbs}$. in. ${ }^{2}$ for one hour. When treated with steam at a pressure of $300 \mathrm{lbs}$./in. ${ }^{2}$ for one hour subsequent to the 150-pound treatment, the total expansions resulting from the two treatments ranged between 0.002 and 0.012 per cent, with an average of 0.005 per cent.

The mat glazes expanded 0.003 to 0.015 per cent with an average of 0.010 per cent when treated with steam at a pressure of $150 \mathrm{lbs}$./in. ${ }^{2}$; and on being subjected to the 300-pound treatment, the total expansions ranged between 0.003 and 0.030 per cent, with an average of 0.017 per cent.

The vitreous slip finishes developed moisture expansions ranging between 0.004 and 0.006 per cent, with an average of 0.005 per cent when treated with steam at 150 pounds; and when subsequently subjected to the 300-pound treatment the total expansions arising from the two treatments ranged between 0.022 and 0.029 per cent, with an average of 0.026 per cent.

The porous slip finishes expanded 0.020 to 0.067 per cent, with an average of 0.033 per cent as a result of the treatment at 150 pounds; when treated at 300 pounds the total expansions from the two treatments were between 0.029 and 0.139 per cent, with an average of 0.078 per cent.

In a previous work ${ }^{6}$ some porous ceramic bodies were found to expand 0.055 to 0.125 per cent as a result of this treatment with steam at 150 pounds for an hour. In comparison, the expansion of one of the mat glazes mentioned above was 0.015 per cent when treated in this way; that is, the expansion of this glaze amounts to between 12.5 and 30 per cent of that developed in the porous ceramic bodies previously tested.

\section{RESULTS WITH CERAMIC FINISHES ON RINGS}

The results shown in Table 2 and obtained with the glazes and other ceramic finishes when they were applied to rings made of the appropriate bodies have in part been plotted in Figures 1 and 2 against the corresponding results in Table 1 . The values obtained by the ring method are too low when the finishes craze since some of the strain between the body and finish is relieved by this crazing; and for this reason some of the data are not included in the figures. It is 
evident from the figures that, in general, those finishes which develop the least moisture expansion caused the rings made from a given body to expand the most when they were treated with steam at $75 \mathrm{lbs} . / \mathrm{in}^{2}{ }^{2}$ for one hour, hence the reciprocals of the expansions of these rings may be used as qualitative indicators of the comparative degrees to which the moisture expansions of the glazes fall short of that of the body represented in the rings.

\section{Expansion of rings (cms)}

caused by treatment with steam at $75 \mathrm{lbs} / \mathrm{in}{ }^{2}$

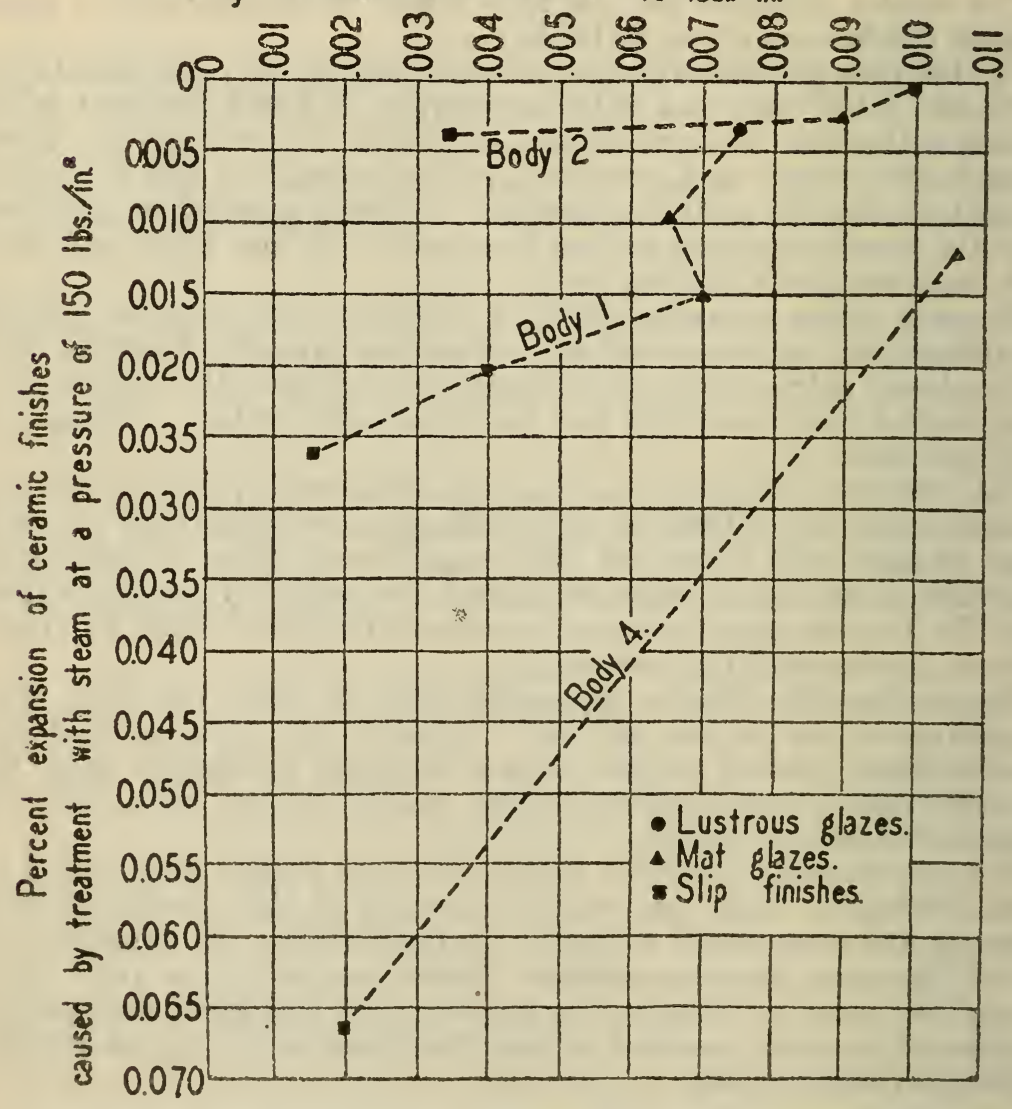

Figure 1.-Comparison of the moisture expansions of ceramic finishes and expansions of rings with these finishes

It must be remembered, however, that the expansion of the rings during an autoclave treatment is also governed to some extent by certain other physical properties of the finishes and bodies, such as, for example, the elasticity and tensile strength. These factors are always important and especially so where there is little or no moisture expansion in the finish to reduce the tensile stresses set up in it by the swelling of the body. Although the moisture expansion tests mado 
on rings are qualitative and not as accurate as tests made on bars of the finishes, the ring test has the advantage over the bar test in that its measurements are made on combinations of glaze and body prepared and treated under conditions almost exactly like those employed on the same combinations when they are prepared for actual use.

\section{Expansion of rings (cms)}

caused by treatment with steam at $75 \mathrm{lbs} . / \mathrm{in}^{2}$

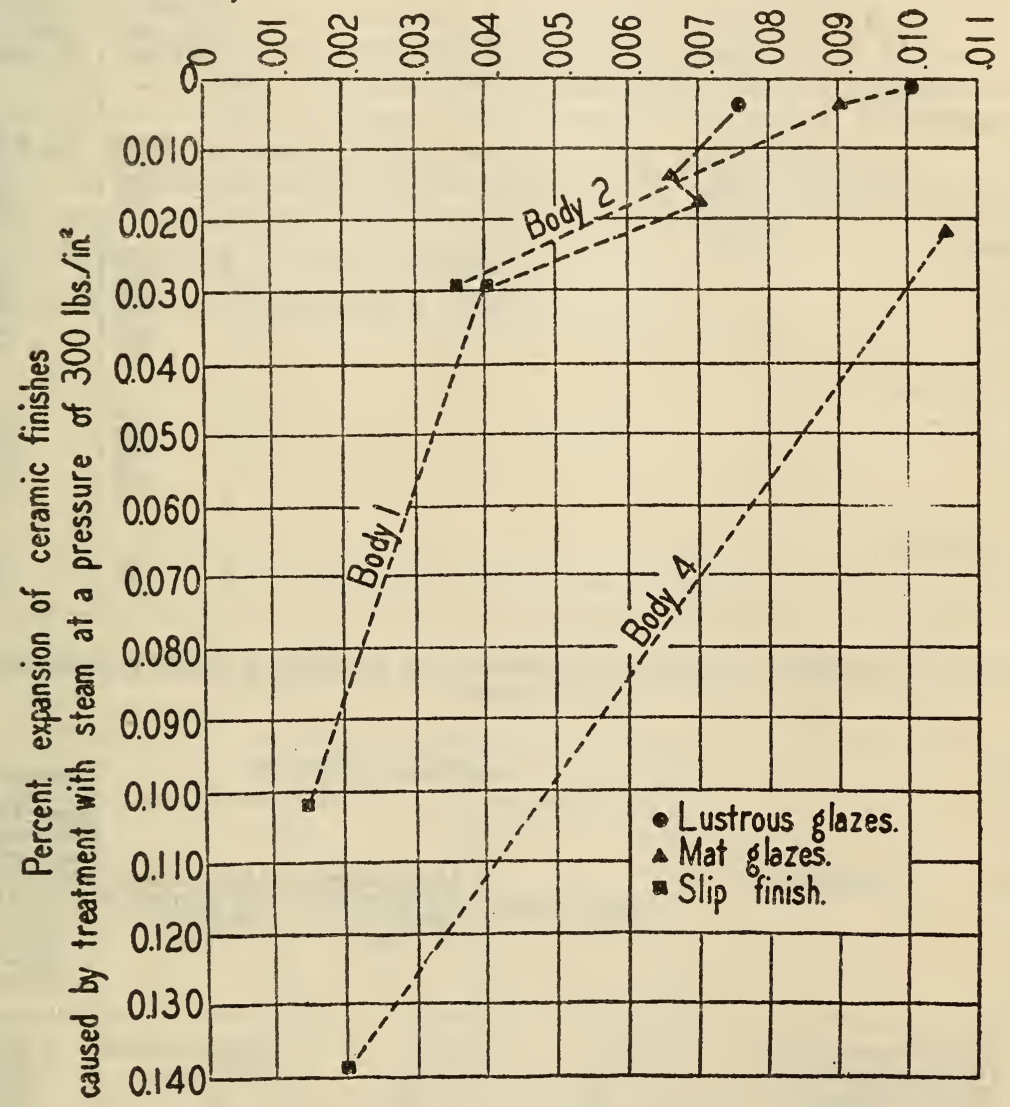

FIGURE 2.-Comparison of the moisture expansions of ceramic finishes and expansions of rings with these finishes

Furthermore, it can be conducted in less time and with less expensive apparatus than that required for the bar test. In employing the ring test to compare moisture expansions of glazes it is, of course, necessary to use the same ring body fired to the same temperature for all of the glazes. 
TABLE 1.-Moisture expansions of glazes and other ceramic finishes when subjected to an autoclave treatment

Lustrous glazes:

D.

Mat glazes:

B.-.

B.

D

F

Porous slip finishes:

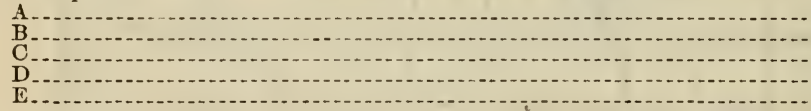

Vitreous slip finishes:

A.

B

\begin{tabular}{|c|c|}
\hline $\begin{array}{l}\text { Expansion } \\
\text { of bars } n \\
\text { and otl } \\
\text { finishes. } \\
3 \text { tests. } \\
\pm 0.0005\end{array}$ & $\begin{array}{l}\text { (in per cent) } \\
\text { ade of glazes } \\
\text { er ceramic } \\
\text { (Average of } \\
\text { Variations }= \\
\text { er cent) }\end{array}$ \\
\hline $\begin{array}{l}150 \mathrm{lbs} / / \mathrm{in} .^{2} \\
\text { steam } \\
\text { pressure } \\
\text { for } 1 \text { hour }\end{array}$ & $\begin{array}{l}300 \text { lbs./in. }{ }^{2} \\
\text { steam } \\
\text { pressure } \\
\text { for } 1 \text { hour }\end{array}$ \\
\hline $\begin{array}{r}0.003 \\
.001 \\
.002 \\
.009\end{array}$ & $\begin{array}{r}0.004 \\
.002 \\
.005 \\
.012\end{array}$ \\
\hline $\begin{array}{l}.015 \\
.009 \\
.003 \\
.013 \\
.012\end{array}$ & $\begin{array}{l}.017 \\
.013 \\
.003 \\
.030 \\
.021\end{array}$ \\
\hline $\begin{array}{l}.020 \\
.026 \\
.030 \\
.020 \\
.067\end{array}$ & $\begin{array}{l}.029 \\
.102 \\
.070 \\
.048 \\
.139\end{array}$ \\
\hline $\begin{array}{l}.004 \\
.006\end{array}$ & $\begin{array}{l}.029 \\
.022\end{array}$ \\
\hline
\end{tabular}

TABLE 2.-The effect of autoclave treatment on the tendency of glazed ceramic ware to craze

\begin{tabular}{|c|c|c|c|c|c|}
\hline \multirow[b]{2}{*}{ Body } & \multirow[b]{2}{*}{ Ceramic finish } & \multicolumn{3}{|c|}{ Appearance of glazed tile } & \multirow{2}{*}{$\begin{array}{l}\text { Expansion } \\
\text { (in cm) of } \\
\text { giazed rings } \\
\text { from treat- } \\
\text { ment with } \\
\text { steam at } 75 \\
\text { lbs./in. }{ }^{2} \text { for } \\
\text { 1 hour. } \\
\text { (Varia- } \\
\text { tion = } \\
\pm 0.001 \mathrm{~cm} \text { ) }\end{array}$} \\
\hline & & Before testing & $\begin{array}{c}\text { After treatment } \\
\text { with steam at } 75 \\
\text { lbs./in. }{ }^{2} \text { for } 1 \\
\text { hour }\end{array}$ & $\begin{array}{l}\text { After treatment } \\
\text { with steam at } 150 \\
\text { lbs./in. } .^{2} \text { for } 1 \\
\text { hour }\end{array}$ & \\
\hline 1 & $\left\{\begin{array}{l}\text { White lustrous glaze A } \\
\text { White mat glaze A } \\
\text { White mat glaze B } \\
\text { Porous slip finish A A } \\
\text { Porous slip finish B }\end{array}\right.$ & 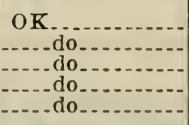 & 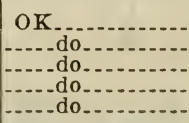 & \begin{tabular}{l} 
Medium crazing \\
OK \\
$-d o$ \\
\\
\hdashline- do do
\end{tabular} & $\begin{array}{r}0.0075 \\
.0070 \\
.0065 \\
.0040 \\
.0015\end{array}$ \\
\hline 2 & $\left\{\begin{array}{l}\text { White lustrous glaze } \mathrm{B} \\
\text { White mat glaze C } \\
\text { Vitreous slip finish }\end{array}\right.$ & 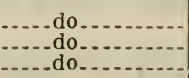 & $\begin{array}{l}\text { (n) } \\
-\ldots \text { do }\end{array}$ & $\begin{array}{l}\text { Badly crazed...- } \\
\text { Slightly crazed.- } \\
\text { Badly crazed..-- }\end{array}$ & $\begin{array}{l}.0100 \\
.0090 \\
.0035\end{array}$ \\
\hline 3 & $\left\{\begin{array}{l}\text { White lustrous glaze on C... } \\
\text { White mat glaze D } \\
\text { Vitreous slip finish } \mathrm{B} \\
\text { Porous slip finish } \mathrm{C}\end{array}\right.$ & $\begin{array}{l}\text { Slightly crazed.. } \\
\text { Medium crazing. } \\
\text { OK-............ } \\
\text { Medium crazing. }\end{array}$ & $\begin{array}{l}\text { Badly crazed.... } \\
\text { OK. } \\
\text { Badly crazed }\end{array}$ & $\mathrm{OK}$ & $\begin{array}{l}1.0075+ \\
.0040 \\
.0015+\end{array}$ \\
\hline 4 & $\left\{\begin{array}{l}\text { White lustrous glaze D.. } \\
\text { White mat glaze } \mathrm{E} \\
\text { Porous slip finish } \mathrm{D} \\
\text { Porous slip finish E.... }\end{array}\right.$ & $\begin{array}{l}\text { Slightly crazed.. } \\
\text { OK. } \\
\text { Slightly crazed.- } \\
\text { OK.............. }\end{array}$ & $\begin{array}{l}\text { Slightly crazed.. } \\
\text { OK. } \\
\text { Slightly crazed.. } \\
\text { OK. }\end{array}$ & Badly crazed.... & $\begin{array}{l}.0045+ \\
.0105 \\
.0090+ \\
.0020\end{array}$ \\
\hline
\end{tabular}

1 The expansions of rings which were crazed are marked plus $(t)$, since some of the strain between the body and slip bas been relieved by crazing of the slip. 


\section{SUMMARY AND CONCLUSIONS}

1. Some mat and lustrous glazes as well as slip finishes expand similarly to porous ceramic bodies from the action of water. This fact is of fundamental importance in fitting glazes to ceramic bodies.

2. In general, slip finishes develop the highest moisture expansions, and when they are treated with steam at a pressure of $150 \mathrm{lbs} . / \mathrm{in}^{2}{ }^{2}$ for one hour the average expansion, as determined by this investigation, amounts to 0.033 per cent. When treated in a similar manner, the average expansion obtained for mat glazes was 0.011 per cent, for vitreous slip 0.005 per cent, and for lustrous glazes 0.004 per cent.

3. The ring test may be used advantageously to compare the approximate moisture expansions of ceramic finishes if the rings are all made from the same body treated in the same manner.

4. The moisture expansions of glazes and other ceramic finishes is often more important with respect to their tendency to craze than their elasticity and tensile strength.

Washington, September 8, 1930. 